\title{
Effect of Flubendazole on Biotransformation Enzymes Activities in Haemonchus contortus
}

\author{
Ivan Vokřála , Veronika Kř́žováa ${ }^{\text {a }}$ Jiří Lamka ${ }^{a}$, Vladimír Kubíček ${ }^{\mathrm{a}}$, Barbora Szotákováa \\ Marian Várady ${ }^{\mathrm{b}}$, Milan Nobilis ${ }^{\mathrm{a}}$ and Lenka Skálová*,a \\ ${ }^{a}$ Charles University in Prague, Faculty of Pharmacy in Hradec Králové, Heyrovského 1203, Hradec Králové, Czech
Republic
${ }^{b}$ Parasitological Institute, Slovak Academy of Sciences, Hlinkova 3, Košice, Slovakia
}

Abstract: The aim of present project was to find out if in vivo contact of Haemonchus contortus with benzimidazole anthelmintic flubendazole (FLU) during treatment of its hosts (sheep) with low doses of FLU affects helminths' drugmetabolizing enzyme activities. Four groups of lambs, experimentally infected with $H$. contortus, were treated three-times orally with $0.0,0.25,0.50$ or $1.00 \mathrm{mg}$ per $\mathrm{kg}$ of body weight of FLU in three consecutive days. Twenty four hours after the last FLU dose, the nematodes were isolated, homogenized and subcellular fractions were prepared. In these subcellular fractions, biotransformation of FLU and the activities of carbonyl reducing enzymes and conjugation enzymes were assayed. The results showed that $H$. contortus enzymes were able to conjugate p-nitrophenol with glucose but not with glucuronic acid. The exposure of H.contortus to FLU (the highest FLU dose) caused a significant increase in activities of FLU reductases, D,L-glyceraldehyde reductases and glutathion S-transferases.

Keywords: Benzimidazoles, drug metabolism, enzyme modulation.

\section{INTRODUCTION}

Biotransformation enzymes in all organisms serve as an efficient defense against potential negative action of xenobiotics. Xenobiotics, including drugs, undergo biotransformation to achieve deactivation and easier excretion. Helminth biotransformation enzymes may thus diminish the final efficacy of anthelmintics. The ability to inactivate anthelmintics via biotransformation can to a certain extent protect these organisms against toxic effects of drugs [1-3].

A contact of organisms with toxic compounds may lead to induction of defensive enzymes, i.e. increased certain enzyme activities via increased expression or protein stabilization. Induction of several biotransformation enzymes by xenobiotics was observed in free living roundworm Caenorhabditis elegans [e.g. 4, 5]. Induction of catalase activities as a response to the oxidative stress was described in $H$. contortus [6]. In the case of anthelmintics, the induction of anthelmintics metabolizing enzymes could increase anthelmintics deactivation in parasites' bodies and by this way facilitate the surviving of some helminth' individuals exposed to anthelmintic therapy [7]. But till now, direct information about induction of helminth' biotransformation enzymes by contact of helminths with anthelmintics have not been reported yet.

The aim of present project was to find out if contact of $H$. contortus with benzimidazole anthelmintic flubendazole (FLU) during treatment of hosts (sheep) with FLU

*Address correspondence to this author at the Department of Biochemical Sciences, Faculty of Pharmacy, Charles University, Heyrovského 1203, Hradec Králové, CZ-500 05, Czech Republic; Tel: 420 495067322; Fax: 420 495067168; E-mail: lenka.skalova@faf.cuni.cz sub-optimal doses (non-lethal for all worms) affects biotransformation enzyme activities and FLU deactivation in survived helminths.

\section{MATERIALS AND METHODOLOGY}

\section{Chemicals}

Flubendazole (FLU) and its two main metabolites (reduced flubendazole, hydrolyzed flubendazole) were provided by Janssen Pharmaceutica (Czech Republic). All other chemicals (HPLC or analytical grade) were obtained from Sigma-Aldrich (Czech Republic).

\section{Experimental Infection of Sheep with Haemonchus con-} tortus

$H$. contortus ISE strain used in this study was an anthelmintic-susceptible inbred strain of SE strain [8], which was isolated from the field before benzimidazole anthelmintics were on the market. The susceptibility of this $H$. contortus ISE strain to FLU was proved using larval development test [9]. Each of the sixteen parasite-free rams of sheep (Ovis aries), 5-6 months old, were orally infected with $5500 \mathrm{~L}_{3}$ larvae of $H$. contortus. The development of $H$. contortus adults was coprologically monitored.

\section{Treatment of Lambs with FLU}

Flubenol (50\% FLU premix, Janssen Pharmaceutica, Belgium) and Avicel RC-591 (microcrystalic cellulose; FMC, Belgium) were used for the preparation of aqueous suspension administered to animals [10].

Eight weeks after the infection, the sheep were divided into four groups (4 animals in each group). FLU-containing or FLU-free suspensions were administered orally using the 
loader for liquid pharmaceuticals. Each animal was treated with three doses administered every 24 hours in three consecutive days. The same volume of the suspension $(0.75 \mathrm{~mL})$ per $\mathrm{kg}$ of body weight was administered to all animals. The animals in Control group were treated with the same suspension without FLU. Each dose administered to animals in the remaining groups contained $0.25 \mathrm{mg}$ (group FLU 0.25), 0.50 $\mathrm{mg}$ (group FLU 0.50) and $1.00 \mathrm{mg}$ (group FLU 1.00) of FLU per $\mathrm{kg}$ of body weight per day. All experiments on animals were approved by the Ethical Committee of Faculty of Pharmacy, Charles University.

\section{Collection of Nematodes}

The nematodes were isolated from host twenty four hours after administration of the last FLU dose. The exposition of nematodes in abomasum to FLU lasted approx. 68-70hours. The animals were stunned and bleeding immediately in agreement with Czech slaughtering rules for farm animals. The abomasa were removed, ligated and transported in a warm bath $\left(38^{\circ} \mathrm{C}\right)$ to the laboratory. Adult nematodes were isolated from the sheep abomasum using agar method [11]. Freshly isolated $H$. contortus adults were washed repeatedly in $0.1 \mathrm{M}$ phosphate-buffered saline $\mathrm{pH} 7.4$ and vivid (moving) worms were quickly frozen to $-80^{\circ} \mathrm{C}$.

\section{Preparation of Subcellular Fractions from Nematodes}

Nematodes (five grams from each sheep group) were thawed at a time and rapidly homogenized at the $\mathrm{w} / \mathrm{v}$ ratio of 1:6 in 0.1 M sodium phosphate buffer, $\mathrm{pH} 7.4$, using a Potter-Elvehjem homogeniser and sonication with Sonopuls (Bandelin, Germany). The subcellular fractions were isolated by fractional ultracentrifugation of the homogenate in the same buffer using the protocol for routine preparation of subcellular fractions from mammals' tissues [12]. Briefly, supernatant after two centrifugations $(5000 \mathrm{~g}$ for $20 \mathrm{~min}$. and $20000 \mathrm{~g}$ for $60 \mathrm{~min}$.) was ultracentrifugated $(105000 \mathrm{~g}$ for 60 min.). Temperature was kept at $2-6^{\circ} \mathrm{C}$ during the whole procedure. Microsomes and cytosol like fractions were represented by $105000 \mathrm{~g}$ sediment and supernatant, respectively, and were stored at $-80^{\circ} \mathrm{C}$. Protein concentrations were assayed using the bicinchoninic acid method according to the Sigma protocol.

\section{Assay of FLU Biotransformation In Vitro}

The cytosol like fractions were incubated in absence or in presence of FLU $(0.5,1.5,3.0,5.0$ and $10.0 \mu \mathrm{M})$. Higher FLU concentration was not used as complete FLU solubility in reaction mixture could not be guaranteed. The reaction mixture (total volume of $0.3 \mathrm{~mL}$ ) contained $100 \mu \mathrm{L}$ of cytosol (containing 0.7-1.0 mg of proteins), FLU pre-dissolved in dimethyl sulfoxide (the DMSO concentration in the reaction mixture was $1 \%)$, NADPH (1 mM) and $0.1 \mathrm{M} \mathrm{Na-phosphate}$ buffer, $\mathrm{pH}$ 7.4. The blank samples contained $100 \mu \mathrm{L}$ of 0.1 $\mathrm{M}$ sodium phosphate buffer, $\mathrm{pH} 7.4$, instead of cytosol. The incubations were carried out at $37^{\circ} \mathrm{C}$ for 30 minutes under aerobic conditions. The product formation was linear up to $60 \mathrm{~min}$. At the end of incubation, $30 \mu \mathrm{L}$ of concentrated ammonium solution and $700 \mu 1$ of cooled ethyl acetate were added, shaken (3 min., vortex) and centrifuged (10 min, $10000 \mathrm{~g})$. Supernatants were evaporated and stored under $20^{\circ} \mathrm{C}$ until HPLC analyses.

\section{HPLC Analysis of FLU and its Metabolites}

Chromatographic analyses were performed with Shimadzu liquid chromatograph comprising a degasser GT-154, solvent delivery module LC-10ADvp, autoinjector SIL10ADvp, column oven CTO-10Avp, UV/VIS photodiode array detector SPD-M10Avp, spectrofluorimetric detector RF-10AXL and system controller SCL-10Avp. The chromatograph was controlled by Shimadzu software CLASSVP. A LiChroCART chromatographic column packed with LiChrospher 60 RP-select B (250 mm x $4 \mathrm{~mm}, 5 \mu \mathrm{m})$ and a precolumn (4 $\mathrm{mm} \times 4 \mathrm{~mm}$ ) packed with the same stationary phase were employed. Following chromatographic conditions were used: the mobile phase was a mixture of acetonitrile and $0.025 \mathrm{M} \mathrm{KH}_{2} \mathrm{PO}_{4}$ buffer, $(3: 7 ; \mathrm{v} / \mathrm{v}), \mathrm{pH}=3$, delivered at a flow rate of $0.7 \mathrm{~mL} / \mathrm{min}$ in isocratic mode. Using the photodiode array detector, the chromatograms were recorded at $246 \mathrm{~nm}$ and $300 \mathrm{~nm}$ (scan $195-380 \mathrm{~nm}$ ). Using the spectrofluorimetric detector the excitation wavelength was $290 \mathrm{~nm}$ and emission wavelength was $320 \mathrm{~nm}$. FLU-H, FLU-R and FLU were detected with the photodiode array detector. The spectrofluorimetric detector served for improving the sensitivity of FLU-R detection (FLU-H and FLU are not fluorescent). Fifty $\mu \mathrm{L}$ of each sample were injected onto the chromatographic column. The duration of the complete analysis was 22 minutes. This analytical method was validated [13] and very low limit of FLU-R quantification $(0.63$ nmol. $\left.\mathrm{L}^{-1}\right)$ was found. Prior to the in vitro incubations, the cytosolic fractions of $H$. contortus from FLU treated animals were tested for the presence of FLU and its metabolites. No traces of FLU, FLU-R or other FLU metabolites were found in either cytosolic fraction.

\section{Enzyme Assays}

Enzyme activities were assayed in the cytosol or microsomes like fractions of $H$. contortus homogenate. Each enzyme assay was performed in triplicates. The amount of organic solvents in the final reaction mixtures did not exceed $0.1 \%(\mathrm{v} / \mathrm{v})$.

The activities of carbonyl reductases/dehydrogenases were tested using the following substrates: 4-pyridinecarboxaldehyde (dissolved in redistilled water), D, Lglyceraldehyde (dissolved in DMSO), and 1-acenaphthenol (dissolved in DMSO). The concentrations of substrates, $\mathrm{NADPH}$ (or $\mathrm{NADP}^{+}$for 1-acenaphthenol) and potassium phosphate buffer, $\mathrm{pH} 6.0$ (or TRIS/ $\mathrm{HCl}$ buffer, $\mathrm{pH} 8.0$ for 1acenaphthenol), were $1 \mathrm{mM}, 0.3 \mathrm{mM}$ and $0.1 \mathrm{M}$, respectively. The $10-50 \mu \mathrm{L}$ of cytosolic fractions (containing 6.4$7.8 \mathrm{mg}$ of proteins per $\mathrm{mL}$ ) were added into the reaction mixture (total volume $1 \mathrm{~mL}$ ). Spectrophotometric determination (detection wavelength $340 \mathrm{~nm}, 25^{\circ} \mathrm{C}$ ) of NADPH consumption or formation in the reaction mixture served for the assessment of reductase/dehydrogenase activities [14-16].

The microsomal UDP-glucuronosyl transferase activity was assayed following the method by Mizuma et al. [17]. Microsomes were preincubated with the Slovasol detergent at $4{ }^{\circ} \mathrm{C}$ for 20 minutes. The reaction mixture (total volume of $0.1 \mathrm{~mL})$ contained $10 \mu \mathrm{L}$ of microsomes $(0.12-0.14 \mathrm{mg}$ of protein), $0.33 \mathrm{mM}$ UDP-glucuronic acid and $166.8 \mu \mathrm{M} p$ nitrophenol (dissolved in redistilled water) in $0.1 \mathrm{M}$ Tris $/ \mathrm{HCl}$ buffer ( $\mathrm{pH} 7.4$ ). After 20 minutes of incubation at $37^{\circ} \mathrm{C}$, the 
reaction was stopped by addition of $50 \mu \mathrm{L} 3 \%$ trichloroacetic acid (v/v). After shaking and centrifugation (3 min., $2000 \mathrm{~g}$ ), $50 \mu \mathrm{L}$ of the supernatant were mixed with $50 \mu \mathrm{L} 1 \mathrm{M} \mathrm{NaOH}$. The absorbance was measured using a BioRad microplate reader (detection wavelength $415 \mathrm{~nm}$ ). The same procedure was used for the testing of microsomal UDP-glucosyl transferase activity using UDP-glucose instead of UDPglucuronic acid.

The cytosolic glutathione S-transferase (GST) activities were assayed using 1-chloro-2,4-dinitrobenzene as a substrate (dissolved in ethanol). The reaction mixture (total volume $1 \mathrm{~mL}$ ) contained $10 \mu \mathrm{L}$ of cytosol $(0.14-0.18 \mathrm{mg}$ of protein), $1 \mathrm{mM}$ reduced glutathione, $1 \mathrm{mM}$ 1-chloro-2,4dinitrobenzene in $0.1 \mathrm{M}$ Na-phosphate buffer $(\mathrm{pH}=6.5)$. The reaction mixture was shaken and the absorbance was measured spectrophotometrically at $340 \mathrm{~nm}$ four times in 60 second intervals [18].

\section{RESULTS AND DISCUSSION}

Benzimidazole anthelmintic FLU is widely used for antiparasitic control in pigs, chicken, turkeys, game birds and domestic carnivores. Efficacy of FLU against roundworms has been also proved in the parasitoses treatment in small ruminants [19] and it is intended for therapy of haemonchosis in sheep.

Metabolism of FLU in $H$. contortus subcellular fractions was firstly studied in our previous project [20]. We found that $H$. contortus enzymes metabolized FLU via reduction of its carbonyl group (Fig. 1) The ability of $H$. contortus enzymes to reduce carbonyl group of xenobiotics was further confirmed using model substrates (D,L-glyceraldehyde, metyrapone, daunorubicin).

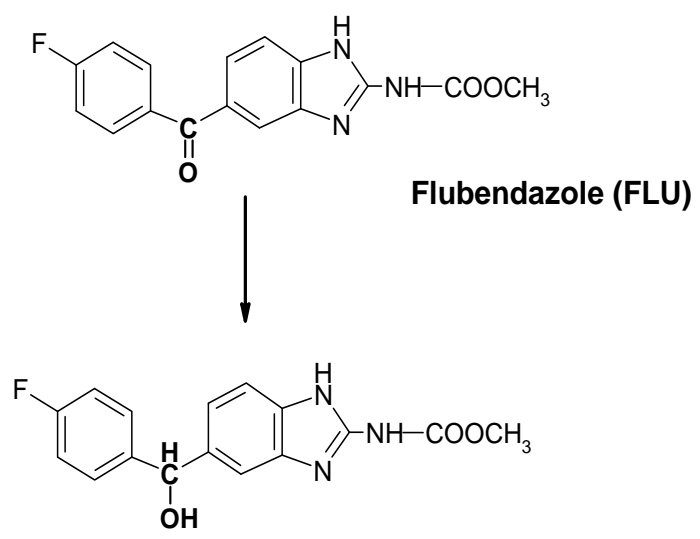

Flubendazole reduced (FLU-R)

Fig. (1). Structure of flubendazole (FLU) and its metabolite reduced FLU (FLU-R).

In farm animals, modulation of biotransformation enzymes via FLU treatment was found [12] but no information about FLU effect on helminth' biotransformation enzymes has been available. The present project was designed to evaluate if repeated in vivo contact of $H$. contortus with low doses of FLU affects $H$. contortus biotransformation en- zymes and FLU metabolism in vitro. Nematodes were obtained from control sheep (Control) or sheep treated in three previous days with 0.25 (group FLU 0.25), 0.50 (group FLU 0.50 ) and 1.00 (group FLU 1.00) $\mathrm{mg}$ of FLU per $\mathrm{kg}$ of body weight per day. The highest dose used lies in range of one third and one tenth of doses, which are recommended as therapeutic ones in monogastric animals [21]. Repeated treatment of animals in three consecutive days was chosen to achieve the exposition time enough for induction of biotransformation enzymes.

Generally, xenobiotic modulates (induces or inhibits) mainly those biotransformation enzymes that catalyze its biotransformation. In presented study, the main attention was paid on carbonyl reductases modulation as FLU is metabolized via carbonyl reduction in $H$. contortus. In vitro activities of carbonyl reductases toward selected model substrates $[15,16,22,23]$ were tested in $H$. contortus cytosol like fractions. The results proved the ability of $H$. contortus enzymes to reduce the carbonyl group of organic compounds. The contact of nematodes in hosts with the highest FLU dose (1.00 mg per kg per day) led to a significant increase only in DL-glyceraldehyde reductase (GALR) activity (see Table 1).

With aim to know if previous contact of helminths with FLU in hosts affect FLU reduction in helminths, the activities of FLU reductases were tested in cytosol like fractions from each nematodes' groups. The results were presented in Fig. (2). The FLU reductases activities were significantly increased (by 25-50\%) in FLU 1.00 group comparing to the Control group when lower concentrations of substrate (FLU) were used in in vitro incubations. But this increase was not detected when a higher concentration of substrate was used in incubations. As several enzymes are able to reduce carbonyl containing xenobiotics [24] this discrepancy could be explained by the participation of at least two enzymes in FLU reduction. Contact of living helminth with FLU probably caused the induction of the one FLU reductase that has a higher affinity but lower capacity to FLU. The activity of second FLU reductase (with lower affinity and higher capacity) was probably not affected and due this fact the induction effect of FLU came out only at lower FLU concentrations.

When FLU biotransformation was studied in $H$. contortus ex vivo, two phase II metabolites of FLU - conjugates of FLU and FLU-R with glucose - were discovered [25]. With respect to this fact, the conjugation enzyme assays were also included in the present project.

$H$. contortus ability to conjugate the model xenobiotic substrate (p-nitrophenol) with UDP-glucose or UDPglucuronic acid was tested in microsomal fractions. The results proved that $H$. contortus enzymes use glucose but not glucuronic acid for conjugation of xenobiotics. This finding is interesting as glucose conjugation, common metabolic pathway in plants, occurs rarely in animal kingdom. Focusing on helminths, only O'Hanlon and coworkers [26, 27] reported glucose conjugation in ecdysteroids metabolism in nematodes Ascaris suum and Parascaris equorum. The contact of $H$. contortus with FLU did not affect UDP-glucosyl transferase activity towards p-nitrophenol since any significant differences among control group and all FLU groups were not found. 
Table 1. Specific Activities of D,L-Glyceraldehyde Reductase (GALR), Acenaphthenol Dehydrogenase (ACND) Nad Glutathione S-Tranferases in $H$. contortus from Sheep Without FLU (Control) and FLU Treated Sheep (FLU 0.25, FLU 0.50 and FLU 1.00)

\begin{tabular}{|c|c|c|c|c|}
\hline $\begin{array}{c}\text { Specific activity } \\
\backslash(\mathbf{n m o l} / \mathbf{m i n} / \mathbf{m g} \text { of proteins })\end{array}$ & Control & FLU 0.25 & FLU 0.50 & FLU 1.00 \\
\hline \hline GALR & $9.1 \pm 1.0$ & $8.2 \pm 3.0$ & $11.3 \pm 2.4$ & $12.2 \pm 0.7^{*}$ \\
\hline ACND & $4.1 \pm 0.4$ & $4.8 \pm 0.2$ & $5.5 \pm 0.3^{*}$ & $3.4 \pm 0.3^{*}$ \\
\hline GST & $257 \pm 17$ & $260 \pm 10$ & $322 \pm 67$ & $340 \pm 73^{*}$ \\
\hline
\end{tabular}

*Statistically significant difference to Control group $(\mathrm{p} \leq 0.05)$.

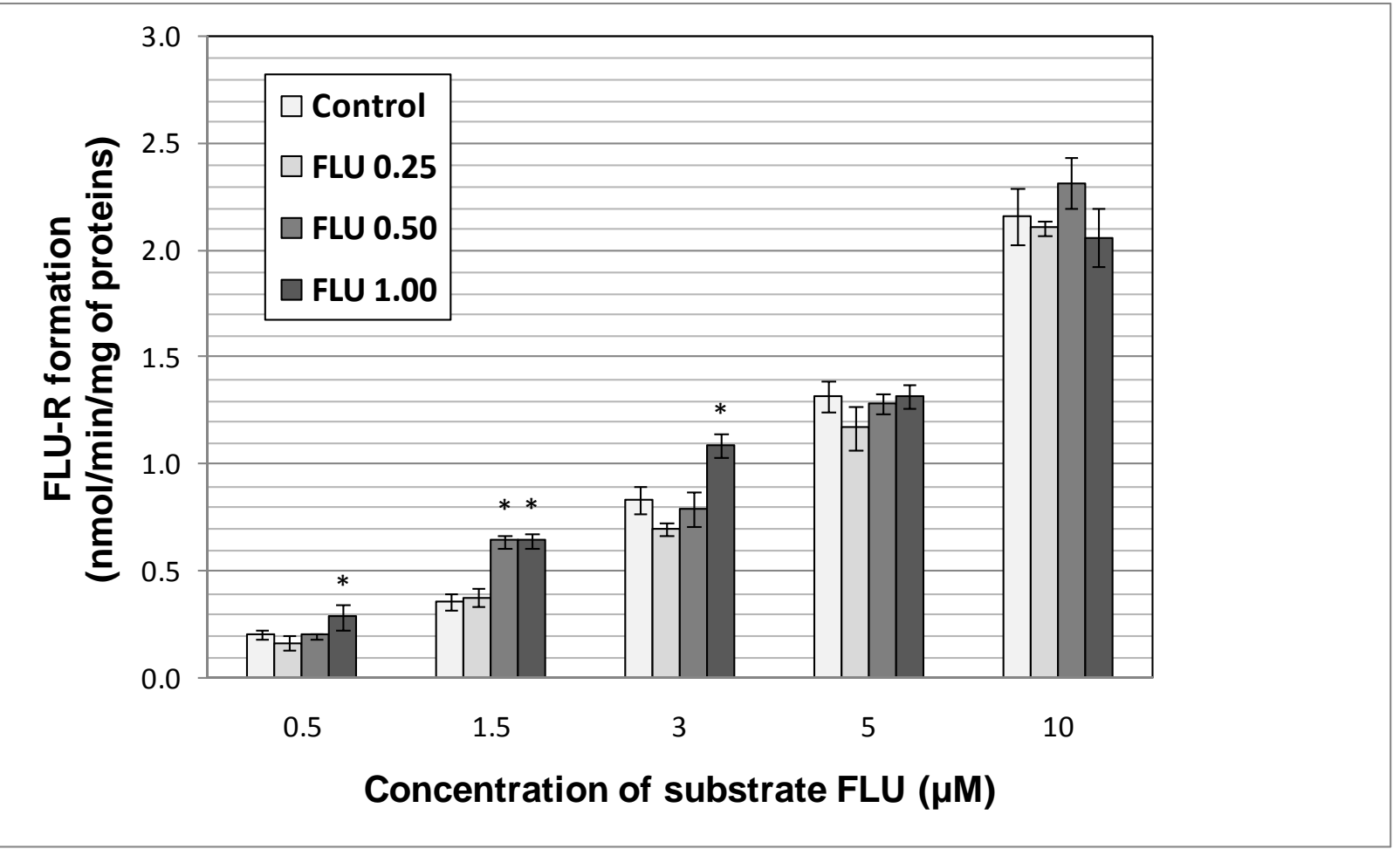

Fig. (2). Specific activities of Haemonchus contortus cytosolic reductases towards flubendazole at various concentrations.

Data represent the means \pm S.D. $(n=4)$.

*Statistically significant difference to Control group $(\mathrm{p} \leq 0.05)$.

While nothing is known about helminth UDP-glucosyl transferases, other conjugation enzymes, glutathione Stransferases (GSTs), have been studied intensively and present knowledge of structure and localization of helminth GSTs is large [e.g. 28]. In spite of this fact, information about GSTs mediated xenobiotics conjugation is rare. Lo and colleagues [29] showed that extracts from Schistosoma mansoni efficiently conjugated synthetically prepared electrophilic compounds with glutathione. Vande Waa et al. [30] found GST activity towards model substrate (1-chloro-2,4dinitrobenzene, CDNB) in Schistosoma mansoni. In present project, relatively high activity in CDNB conjugation with glutathione was observed in $H$. contortus cytosolic fractions. This specific activity was similar to those found in hepatic cytosol from several mammalian species [31].

When $H$. contortus nematodes were in contact with the highest FLU concentration in vivo (group FLU 1.00), helminth' in vitro GST activity was significantly increased, approximately by $30 \%$ (see Table 1) The induction of GST activity could be caused by oxidative stress arising during FLU effect over the parasite. Classical inducer, phenobarbital, induced GST activity in Hymenolepis diminuta, Echinococcus granulosus and Schistosoma mansoni and other model inducers, 3-methylcholanthrene and butylated hydroxyanisole, significantly induced GST activity against CDNB in Schistosoma mansoni [30, 32, 33]. The increase in GST activities caused by the aforementioned inducers was much more substantial than that caused by FLU in the presented study. On the other hand, FLU is the only anthelmintic, the ability of which to induce the GST was found in helminths.

Although the observed increase of in vitro carbonyl reducing enzymes and GST activities in nematodes previously in vivo exposed to FLU was only slight (but significant), this is the first indication that a contact of $H$. contortus with FLU in hosts may lead to an induction of some biotransformation 
enzyme activities of parasites. The increased ability to deactivate FLU may facilitate the surviving of some $H$. contortus worms under anthelmintic therapy. If more worms survive, the reproduction of those specimens with higher FLU tolerance is more probable. By this way, induction of biotransformation enzymes might represent additional mechanism contributing to development of drug-resistant $H$. contortus strain.

\section{ACKNOWLEDGEMENTS}

Financial support of this project was provided by Czech Science Foundation, Grant No. P502/10/0217.

\section{REFERENCES}

[1] Alvinerie M, Dupuy J, Eeckhoutte C, Sutra JF, Kerboeuf D. In vitro metabolism of moxidectin in Haemonchus contortus adult stages. Parasitol Res 2001; 87: 702-4.

[2] Robinson MW, Lawson J, Trudgett A, Hoey EM, Fairweather I. The comparative metabolism of triclabendazole sulphoxide by triclabendazole-susceptible and triclabendazole-resistant Fasciola hepatica. Parasitol Res 2004; 92: 205-10.

[3] Kotze AC, Dobson RJ, Chandler D. Synergism of rotenone by piperonyl butoxide in Haemonchus contortus and Trichostrongylus colubriformis in vitro: Potential for drug-synergism through inhibition of nematode oxidative detoxification pathways. Vet Parasitol 2006; 136: 275-82.

[4] Menzel R, Bogaert T, Achazi R. A systematic gene expression screen of Caenorhabditis elegans cytochrome P450 genes reveals CYP35 as strongly xenobiotic inducible. Arch Biochem Biophys 2001; 395: 158-168.

[5] Menzel R, Rödel M, Kulas J, Steinberg CEW. CYP35: xenobiotically induced gene expression in the nematode Caenorhabditis elegans. Arch Biochem Biophys 2005; 438: 93-102.

[6] Kotze AC. Catalase induction protects Haemonchus contortus against hydrogen peroxide in vitro. Int J Parasitol 2003; 33: 393400.

[7] Brennan GP, Fairweather I, Trudgett A, et al. Understanding triclabendazole resistance. Exp Mol Pathol 2007; 82: 104-9.

[8] Roos MH, Otsen M, Hoekstra R, Veenstra JG, Lenstra JA. Genetic analysis of inbreeding of two strains of the parasitic nematode Haemonchus contortus. Int J Parasitol 2004; 34: 109-15.

[9] Bártíková H, Lamka J, Skálová L, Szotáková B, Várady M. The effects of flubendazole and its metabolites on larval development of Haemonchus contortus (Nematoda: Trichostrongylidae): an in vitro study. Acta Parasitol 2010; submitted

[10] Šavlík M, Poláčková L, Szotáková B, Lamka J, Velík J, Skálová L. Activities of biotransformation enzymes in pheasant (Phasianus colchicus) and their modulation by in vivo administration of mebendazole and flubendazole. Res Vet Sci 2007; 83: 20-26.

[11] Van Wyk JA, Gerber HM, Groeneveld HT. A technique for recovery of nematodes from ruminants by migration from gastrointestinal ingesta gelled in agar: large-scale application. J Vet Res 1980; 47: 147-158.

[12] Gillete JR. Techniques for studying drug metabolism in vitro. In: La Du BN, Mandel HG, Way EL, Eds. Fundamentals of drug metabolism and drug disposition. Baltimore, The Williams \& Wilkins Company 1972; 400-18.

[13] Kubíček V, Soukupová M, Nobilis M, Kř́žová V, Szotáková B, Skálová L. LC with fluorimetric detection for sensitive analysis of reduced flubendazole in biological samples. Chromagraphia 2008; 68: 865-7.

[14] Feldsted RL, Bachur NR. Mammalian carbonyl reductases. Drug Metab Rev 1980; 11: 1-60.

[15] Ohara H, Miyabe Y, Deyashiki Y, Matsuura K, Hara A. Reduction of drug ketones by dihydrodiol dehydrogenases, carbonyl reductase and aldehyde reductase of human liver. Biochem Pharmacol 1995; 50: 221-7.

[16] Palackal NT, Lee SH, Harvey RG, Blair IA, Penning TM. Activation of polycyclic aromatic hydrocarbon trans-dihydrodiol proximate carcinogens by human aldo-keto reductase (AKR1C) enzymes and their functional overexpression in human lung carcinoma (A549) cells. J Biol Chem 2002; 277: 2479-80.

[17] Mizuma T, Mashida M, Hayashi M, Awazu S. Correlation of drug conjugative metabolism rates between in vivo and in vitro: glucuronidation and sulfation of p-nitrophenol as a model compound in rat. J Pharmacobiodyn 1982; 5: 811-817.

[18] Habig HW, Jacoby BW. Glutathion S-transferases (rat and human). Methods Enzymol 1981; 77: 218-404.

[19] Lamka J, Nevole Z, Ducháček L, Velík J, Zavřel S. The comparison of mebendazole and flubendazole anthelmintic efficacy in experimental treatment of mouflon (Ovis musimon) muelleriosis. Vet Med Czech 2000; 45: 45-48.

[20] Cvilink V, Kubíček V, Nobilis M, et al. Biotransformation of flubendazole and selected model xenobiotics in Haemonchus contortus. Vet Parasitol 2008; 151: 242-8.

[21] Bishop Y. The Veterinary Formulary. 5th ed. Pharmaceutical Press 2001.

[22] Kawamura M, Eisenhofer G, Kopin IJ, et al. Aldose reductase, a key enzyme in the oxidative deamination of norepinephrine in rats. Biochem Pharmacol 1999; 58: 517-24.

[23] Penning TM. Introduction and overview of the Aldo-keto reductase superfamily. ACS Symposium Series 2004; 865: 3-20.

[24] Testa B. The metabolism of drugs and other xenobiotics: Biochemistry of redox reactions. London, Academic Press 1995.

[25] Cvilink V, Skálová L, Szotáková B, Lamka J, Kostiainen R, Ketola R. LC-MS-MS identification of albendazole and flubendazole metabolites formed ex vivo by Haemonchus contortus. Anal Bioanal Chem 2008: 391; 337-3.

[26] O'Hanlon, GM, Howarth OW, Rees HH. Identification of ecdysone 25-O-beta-D-glucopyranoside as a new metabolite of ecdysone in the nematode Parascaris equorum. Biochem J 1987; 248: 305-7.

[27] O'Hanlon GM, Mercer JG, Rees HH. Evidence for the release of 20-hydroxyecdysone 25-glucoside by adult female Parascaris equorum (Nematoda) in vitro. Parasitol Res 1991; 77: 271-2.

[28] Torres-Rivera A, Land A. Glutathione transferases from parasites: A biochemical view. Acta Tropica 2007; 105: 99-112.

[29] Lo WJ, Chiou YC, Hsu YT, et al. Enzymatic and nonenzymatic synthesis of glutathione conjugates: application to the understanding of a parasite's defense system and alternative to the discovery of potent glutathione S-transferase inhibitors. Bioconjug Chem 2007; 18: 109-20.

[30] Vande WEA, Campbell C, Oleary K, Tracy JW. Induction of Schistosoma mansoni glutathione S-transferase by xenobiotics. Arch Biochem Biophys 1993; 303: 15-21.

[31] Szotáková B, Baliharová V, Lamka J, et al. Comparison of in vitro activities of biotransformation enzymes in pig, cattle, goat and sheep. Res Vet Sci 2004; 76: 43-51.

[32] Brophy PM, Barrett J. Blocking factors and the isolation of glutathione transferases from Hymenolepis diminuta (Cestoda: Cyclophyllidea). Parasitology 1990; 100: 137-41.

[33] Morello A, Repetto Y, Atias A. Characterization of glutathione Stransferase activity in Echinococcus granulosus. Comp Biochem Physiol B 1982; 72: 449-52. 